\title{
Characterizing and Explaining Smallholder Households' Views and Understanding of Climate Change in the Bongo District of Ghana
}

\author{
Philip Aniah" ${ }^{1, ~ *, ~ M i l l a r ~ K a t h e r i n e ~ K a u n z a-N u-D e m ², ~ B e r n a r d ~ A w i n b u g r i ~ A b i n d a w ~}{ }^{1}$, David Millar ${ }^{3}$ \\ ${ }^{1}$ Department of Development Studies, Faculty of Integrated Development Studies, University for Development Studies, Wa, Upper West \\ Region, Ghana \\ ${ }^{2}$ Department of Planning, Faculty of Planning and Land Management, University for Development Studies, Wa, Upper West Region, Ghana \\ ${ }^{3}$ Department of African and General Studies, University for Development Studies, Wa, Upper West Region, Ghana
}

Email address:

philipaniah@yahoo.co.uk (P. Aniah)

${ }^{*}$ Corresponding author

\section{To cite this article:}

Philip Aniah, Millar Katherine Kaunza-Nu-Dem, Bernard Awinbugri Abindaw, David Millar. Characterizing and Explaining Smallholder Households' Views and Understanding of Climate Change in the Bongo District of Ghana. Earth Sciences. Vol. 5, No. 2, 2016 , pp. 26-38. doi: 10.11648/j.earth.20160502.12

Received: March 17, 2016; Accepted: March 25, 2016; Published: May 4, 2016

\begin{abstract}
Africa is amongst the most susceptible regions to climate change and this situation is intensified by the interaction of 'multiple stresses' and the low adaptive capacity of smallholder households. Agricultural production and livelihood security in many African countries are severely weakened by climate change. The paper seeks to contribute to the growing empirical and policy discourse on climate change by examining smallholder households' views and understanding of climate change. The research combined qualitative methods (FGD's, historical timelines and interviews) with a quantitative method (survey) and analyzed the data using descriptive and inferential statistics such as percentages, trend analysis and bivariate correlations to investigate the relationships and differences of the variables. The results indicate that smallholder households believe that the rainfall pattern of the Bongo district is characterized by erratic rainfall, reduced rainfall, late onset, short duration and high temperature which have resulted in significant crop failure. The results further show that smallholder households associate climate change to bush burning, deforestation \{hegemonic representation\} whiles others associate climate change to breaking of taboos and the disrespect for the beliefs, spirits, gods (life forces) \{polemic representation\}. Over $95 \%$ of household believe climate change poses severe negative consequences for their farming activities and livelihoods \{emancipated representation\}. These perceptions by smallholder households were corroborated by rainfall and temperature records from the Ghana Meteorological Agency in the Bongo district. Livelihood diversification strategies, including off-farm income sources should be robustly pursued and more specific and targeted climate adaptation policies needs to be formulated by policy makers to reduce the vulnerabilities of smallholder households whose livelihoods depend largely on rain-fed agriculture.
\end{abstract}

Keywords: Climate Change, Smallholder Households, Perceptions, Social Representations, Bongo District, Ghana

\section{Introduction}

Africa is amongst the most susceptible regions to climate change; this situation is intensified by the interaction of 'multiple stresses' which takes place at different degrees as well as the low adaptive capacity of smallholder households [7]. Agricultural production and livelihood security in many African countries are expected to be severely weakened by climate change. Changes in a variety of ecosystems are already being detected, particularly in Sub-Sahara African ecosystems, at a faster rate than anticipated. For instance, Dietz et al. (2004), observed changes in the natural vegetation (for instance the steady loss of the economically vital dawadawa and shea trees), lesser water 
availability/reliability and an alteration in the planting season in Ghana.

The agricultural sector is a critical mainstay of local livelihoods and national GDP in many countries in Africa. The agriculture sector in Ghana employs about $57 \%$ of the population and it is the major source of income for the majority of low income Ghanaian families' most especially rural households [14], not all, the sector also contributes significantly to the foreign exchange earnings of the country and development by means of providing raw materials to local industries [26]. Despite these enormous contributions, the sector is sensitive to climate change through its reliance on rain-fed cultivation [3]. In many parts of Africa for that matter Ghana, farmers and pastoralists also have to contend with other extreme natural resource challenges and constraints such as poor soil fertility, pests, crop and animal diseases, and a lack of access to inputs and improved seeds. These challenges are usually compounded by periods of prolonged droughts and/or floods and are often particularly severe during the growing season [36].

This thesis assessed smallholder households' perceptions of climate change at the community level corroborated by meteorological data. To explain and validate farmers' perceptions about climate change, the study looked at how climate data recorded at the Ghana Meteorological Agency weather stations (Vea weather station) evolved (trends and variability) and how smallholder households perceived these changes.

There is great uncertainty surrounding long-term patterns of climate change, environmental variability and their likely negative impacts on the livelihood activities of smallholder households [3]. The predicted consequences of climate change are diverse. Climate change will inflict harsh and extreme negative impacts on the livelihoods of smallholder households hence existing policy attempts to poverty alleviation could be undermined.

The paper seeks to contribute to the growing empirical and policy discourse on climate change by examining smallholder households' views and understanding of climate change. The paper presents empirical evidence to argue that smallholder households' perceptions of climate change such as rising temperatures with erratic and declining mean rainfall are authentic and that climate change indeed presents severe negative effects for smallholder households.

\section{Theoretical Underpinnings}

\section{Social Representations of Climate Change}

Social sciences approaches to climate change are focused on comprehending how climate change is represented/ characterized in society and how people believe and feel about it. This theoretical model endeavors to tackle both of these issues within an integrated context that draws upon Social Representations Theory (SRT). SRT considers critically vital the information that circulates in society (e.g. in the media, textbooks and literature) and the ideas in people's minds [27]. SRT provides a framework for understanding and exploring how scientific knowledge, such as that associated with the climate change debate, diffuses in society and can become associated with intergroup power struggles. A social representation is defined as a system of values, ideas and practices regarding a given social object, as well as the elaboration of that object by a group for the purpose of communicating and behaving. Accordingly, it provides a given group with a shared social 'reality' and 'common consciousness' vis-àvis a particular social object [17].

[27] has postulated three types of social representation: hegemonic, emancipated and polemic. A hegemonic representation is one that is shared consensually by members of a group; they are coercive and uniform. The notion that the climate is changing largely, as a result of human-induced industrial developments in the Western world constitutes a hegemonic representation within the global scientific community [17]. An emancipated representation is developed by subgroups within a larger social collective as a result of outgrowths of information and distinctive knowledge within these subgroups. Emancipated representations constitute 'developments' or minor amendments of the over-arching hegemonic representation. For instance, while the hegemonic representation is that anthropogenic climate change will have negative outcomes, an emancipated representation, for instance, among Maldiveans (a subgroup within the superordinate community of 'believers') is that climate change is likely to result in the complete submergence of the Maldives resulting in a massive refugee problem [17:5]. A polemic representation is one which is generated in the course of social conflict, and characterized by antagonistic relations between groups. A vivid example of this is the rivalry between the majority of climate scientists, who argue that climate change is dangerous and largely dependent upon human activities, and climate critics, who challenge the legitimacy of this hegemonic representation [17:11].

Hegemonic, emancipated and polemic representations seem to affect the climate change agenda differently. Hegemonic representations are usually more likely to shape attitudes because they are coercive, shared at a mass scale and thus difficult to re-construe or reject [9]. Conversely, polemic representations are often perceived as being peripheral to 'mainstream' thinking and thus unworthy of attention [17]. The representational field in which climate change as a social and cultural issue is located seems to be characterized by all three kinds of social representation [15]. Polemic representations can rise in prominence and gradually become hegemonic partly due to the media's balancing norms, whereby 'both sides of the story' are presented in order to safeguard 'objectivity' [8]. The psychologically preferable, though scientifically indefensible representation may ultimately be adopted by the general population. Conversely, the representation that is grounded in science and empiricism may be ousted from its hegemonic position. 


\section{Methodology}

\subsection{Profile of Study Area}

The natural vegetation of the Bongo district is the savannah woodland, characterized by short scattered drought-resistant trees and grass that gets burnt by bushfire or scorched by the sun during the long dry season. Human interference with ecology is significant, resulting in near semi-arid conditions [2]. The most common economic fruit trees are the shea nut, dawadawa, baobab and acacia [14]. The climate is characterized by one rainy season from May/June to September/October. The mean annual rainfall during this period is between $800 \mathrm{~mm}$ and $1,100 \mathrm{~mm}$. The rainfall is erratic spatially and in duration. There is a long spell of dry season from November to mid-February, characterized by cold, dry and dusty Harmattan winds. Temperatures during this period can be as low as 14 degrees centigrade at night, but can go to more than 35 degrees centigrade during the daytime [14]. Humidity is, however, very low, making the daytime high temperature less uncomfortable. The region is entirely within the "meningitis belt" of Africa. It is also within the onchocerciasis zone, but with the control of the disease, large areas of previously abandoned farmlands have been declared suitable for settlement and farming [14].

According to the [14], agriculture, hunting and forestry are the main economic activities in the Bongo district of the UER. About eighty percent ( $80 \%)$ of the economically active population engages in agriculture. The main produce is millet, guinea-corn, maize, groundnut, beans, sorghum and dry season tomatoes and onions. Livestock and poultry production are also important sources of livelihood for the people. Industrial activity in the region is generally low, with only one industry in operation at the moment. This is the cotton ginnery at Pusu-Namongo (near Bolgatanga). Other industrial establishments are the Tomato Canning Factory (GIHOC) at Pwalugu, the Meat Processing Factory (GIHOC) at Zuarungu and the Rice Mills at Bolgatanga, which are not operational and have been earmarked for divestiture [14].

\subsection{Selections of Study Region and District}

Previous research by [3:117] revealed that, within Ghana, the Upper East Region (UE/R) profiled the topmost mean vulnerability index for the period 2007 to 2010 , hence the choice of the UE/R. The selection of the study district began with an appraisal of production/yields data obtained from MoFA (from 2000 to 2014), to establish the most susceptible district in the UE/R to climate change and related extremes. The Bongo district was tinted as the most vulnerable district in the UE/R based on the scrutiny of crop yield data from MoFA hence its selection.

\subsection{Selection of the Study Communities}

After selection of the study district, a baseline survey was conducted to select the specific communities for the study. Stakeholder and expert interviews were conducted by organizing meetings with the MoFA director at the Bongo district, agriculture extension officers and NGOs working with rural communities in the district (e.g. SUFAEP, CID, and NABOCADO). Grounded on available information, the following criteria were used for the selection of specific farming communities; (i) the community should have been or is being exposed to some sort of climate anomaly (particularly drought); (ii) it should have characteristics that could be researched in line with the study's objectives; and (iii) the community must be prepared to partake in the study during its entire period. Based on consultation with local experts and advice that was provided by agricultural extension officers, stakeholders such as NGOs, and local census data where this exists, two (2) specific communities' vulnerable and resilient communities were selected. They include the Gowrie Kunkua community (vulnerable) and the Soe Kabre community (resilient).

\subsection{Selection of Research Participants}

The total number of households in the two (2) communities was about 400 , for a sample population of about 400 , using the sample size table at the $95 \%$ confidence level and a $5 \%$ margin of error, the sample was 146 households $[13,5]$. For fear of missing data, 150 sample size was determined to fill the questionnaire. To support this view, [5] indicated that it is wise to oversample in case there is missing data. In all, 150 household surveys were conducted in the two (2) studied communities (75 questionnaires in each). Although random sampling was used, factors such as age, gender, and farming experience were considered in order to have a representative of the various social groups within each community and to ensure people with in-depth knowledge on the theme are recruited (the aged) hence a minimum of 30 years was the age limit.

\subsection{Sources and Methods of Data Collection}

This research combined qualitative method (Focus Group Discussion's, historical timelines and interviews) with a quantitative method (traditional survey) to gather the data. 150 semi-structured questionnaires were administered in the two selected communities (75 each). Six (6) Focus Group Discussions (FGDs) were conducted three (3) at Gowrie Kunkua and three (3) at Soe Kabre). Discussions were audiorecorded and field notes were taken at the same time, so as to capture and report the details of the discussions as accurately as possible. A total of fifteen (15) key informant interviews were conducted. Community leaders such as the Tindaana (earth priest), chiefs, elders, assembly members, model farmers and institutional heads such as MoFA director, EPA and GMA were interviewed. These interviews permitted comprehensive and detailed discussion and substantiation/authentication of the focal issues that were tainted by the household questionnaire survey and focus group discussions.

Both primary and secondary sources were used to gather data. [20:101] defines primary data, as the data that lie 
closest to the source of the "ultimate truth" underlying a phenomenon. Beyond the region of primary data lies the region of secondary data. Hence, the primary sources were the individuals and groups who were interviewed using various tools and techniques at the different levels of the data collection process. The secondary sources, however, was drawn from documented evidence which included normally books, journals, publications, office reports and profiles of districts as well as speeches from important personalities relating to the subject.

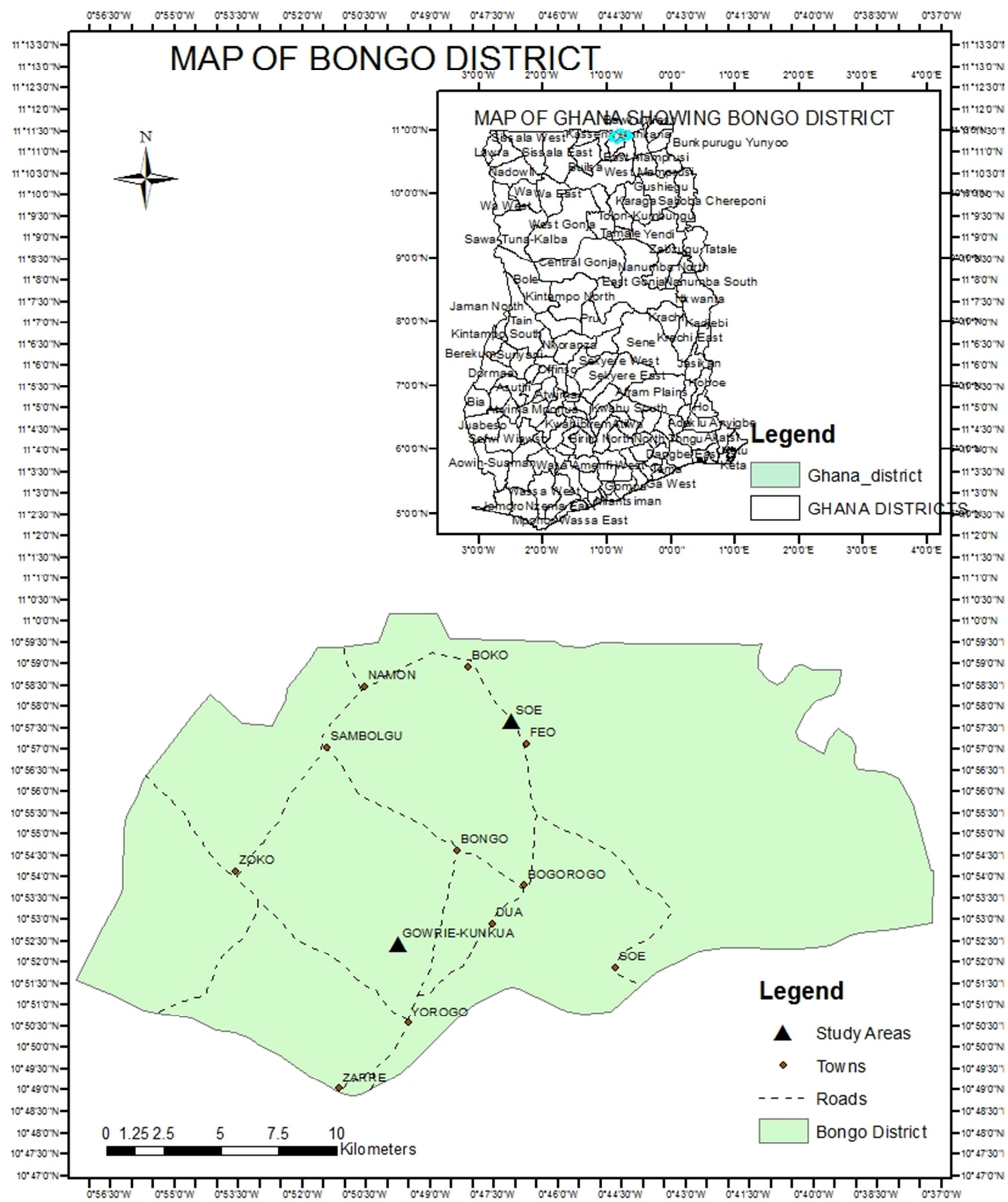

Source: This study

Figure 1. Map showing the study communities in the Bongo district. 


\subsection{Data Analysis}

During the fieldwork, interviews and focus group discussions were audio-recorded and notes were also taken with the help of a field assistant. After each field visit, the reports were written based on the field notes and all the audio recordings were transcribed in the exact words of the respondents. These were then classified into themes under the different case categories and synthesized using descriptive narratives to reflect the collective worldview of communities as the basis for evaluating and characterizing their views and understanding (social representations) of climate change.

The quantitative data analysis, on the other hand, the data were coded, edited, digitized and entered into the statistical package SPSS (Statistical Package for Social Scientists) and analyzed using descriptive and inferential statistics such as frequencies, percentages and tables. Inferential statistics such as paired t- test, chi-square and bivariate correlations were used to investigate the relationships and differences of the variables. To determine the magnitude of climate change in the Bongo district, a time series/trend analysis was conducted for temperature and rainfall information obtained from the Ghana Meteorological Agency spanning the period 1982-2012. The time series/trend analysis has validated assertions via oral history as well as climate timelines that were constructed during FGDs with smallholder households.

\section{Results and Discussions}

\subsection{Smallholder Household Perception About Changes in Rainfall Pattern}

When asked "have rainfall pattern changed in your lifetime", $98.7 \%$ (or 74) of respondents said yes they have observed changes in the rainfall pattern in the Gowrie Kunkua community whiles $92 \%$ (or 69) respondents in the Soe Kabre community observed changes in the rainfall pattern. Pearson correlation (0.158) showed a weak correlation between observed changes in rainfall between the vulnerable and resilient communities statistically significant (at $\mathrm{p}<0.005$ ). Among households or respondents who observed changes in the rainfall pattern, $96 \%$ (or 72) respondents perceived a decrease or reduction in rainfall amount in the Gowrie Kunkua community whiles $88 \%$ (or 66) respondents in the Soe Kabre community perceived a decrease or reduction in rainfall amounts over their life time. $2.7 \%$ detected/perceived an increase and $1.3 \%$ perceived rainfall to be the same in the vulnerable community. Whiles $0 \%$ perceived an increase and $12 \%$ perceived the rainfall pattern to be the same in the resilient community as shown in Figure 2. A Pearson correlation $(\mathrm{R}=0.240)$ showed a weak correlation between households perception of rainfall amount between the vulnerable and resilient communities statistically significant (at $\mathrm{p}<0.005)$.

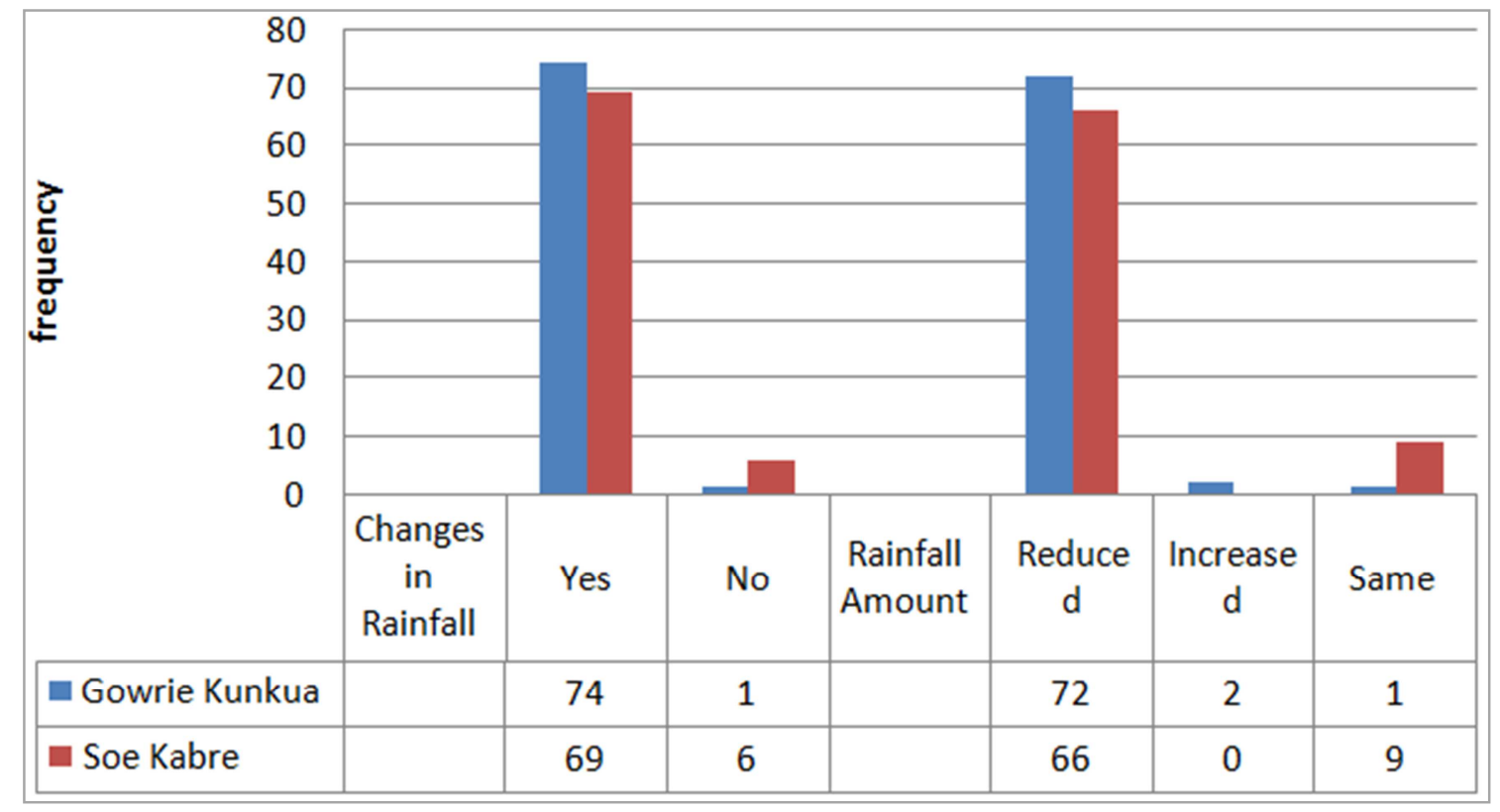

Source: Field Survey, July 2015.

Figure 2. Smallholder Households Perception about Changes in Rainfall Pattern and Rainfall Amount.

In total, among the respondents who observed changes in rainfall patterns over their lifetime, $92 \%$ (or 138) noticed a decrease in the amount of rainfall, $1.3 \%$ (or 2) observed an increase in rainfall amount whiles $6.7 \%$ (or 10 ) perceived the rainfall amount to be the same over their lifetime. A study conducted by [28], observed that, $95 \%$ of farmers in that study indicated that they have observed changing trends in weather patterns. The respondents singled out increasingly unpredictable trends in rainfall distribution as the major change they have witnessed during their lifetime. This 
observation by [28] is in tandem with this present study. [22] observed a significant correlation between farmers' belief about the reality of climate change, concerns (risk perceptions) and their willingness to adapt or to carry adaptation/mitigation course of action. In this study, 51.7\% of households that perceived changes in rainfall pattern implemented adaptation/coping strategies whiles $48.3 \%$ of household who perceived changes in rainfall pattern did not adopt or implement adaptation strategies. Also, 42.9\% (3 out of a total of 7) of households who did not perceive/observed any changes in rainfall implemented adaptation strategies whiles the rest $57.1 \%$ (or 4 ) who did not observe any changes in rainfall did not implement any form of coping or adaptation strategies.

In a FGD, discussant when asked whether they have observed changes in rainfall pattern over their lifetime, affirmed that, "Yes, we have observed changes in the rainfall pattern since our childhood time; there has been irregularity and variations in the temperature and rainfall pattern." Other participants observed that, "It used to rain heavily in the past but now the rainfall pattern has reduced". Generally, communities have observed changes in the rainfall pattern which they said has reduced. Households face a lot of risks posed by this decreasing rainfall amount and erratic pattern. The study revealed that, households who believe in climate change express concerns that climate change will negatively affect farming and their livelihoods. Secondly, households that have experienced adverse weather conditions (e.g., drought or floods) in times past were more likely to implement coping and adaptation strategies.

Households in the study communities perceived that there has been a decline in rainfall and an increase in temperature for decades. In relation to this, [24], [6], indicated that households generally agreed that temperature has increased, cold periods have become shorter and the hot season has extended over longer periods. This is a revelation that farmers are able to recognize the changes in temperature and rainfall in their localities using their indigenous knowledge. The key indicators of a varying climate, according to a FGD were related to the farming activities in the study communities. Drought, floods, reduction in rainfall amount, delay and erratic rainfall regime, hot temperature and availability of pest and diseases are the major pointers of climate change perceived by households. Amongst indicators identified, household survey respondents and Key informants both labeled drought and erratic rainfall as the major indicators of climate change in the district. Discussant at a FGD held that rainfall was the most unreliable and tremendously uneven and hence exceedingly unsatisfactory among the indicators. Similar studies in other parts of the world showed that $99 \%$ of respondents indicated they witnessed the irregularity of rainfall amount and distribution during the main rainy season [29].

\subsection{Smallholder Household Perception About the Onset of the Rains and Its Effects}

In all the two communities studied, $92.7 \%$ (or 138) of households perceived a shorter rainy season with late onset whiles $1.3 \%$ (or 2 ) of households perceived the contrary, early onset and 6\% (or 9) of households perceived the onset of the rains to be the same (neither late nor early) as shown in Figure 3 . With regards to the problems of a varying climate on farming activities, $93.3 \%$ (or 140) of households in the two communities studied perceived the changes in rainfall to have problems for farming activities \{emancipated representation $\}$ whiles the remaining $6.7 \%$ (or 10 ) perceived the changes in rainfall not to have any problem for farming activities \{polemic representation\}.

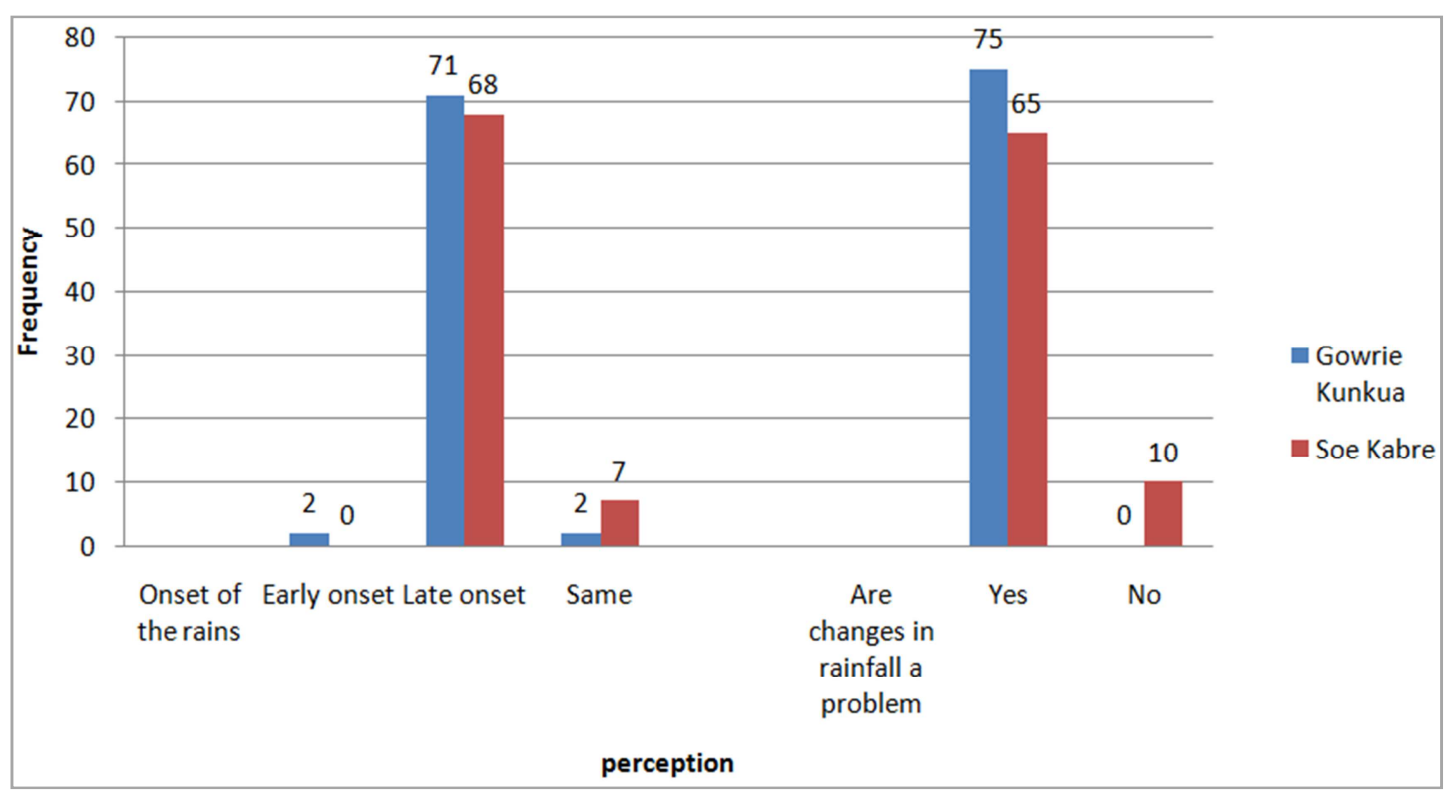

Source: Field Survey, July 2015.

Figure 3. Farmers Perception about Onset of Rainfall and the Effects for Farming Activities. 
Perceived onset and its implication for farming activities varied between the two communities, in the vulnerable community, $2.7 \%, 94.7 \%$ and $2.7 \%$ of households perceived the onset of the rainfall pattern to be early onset, late onset and same onset (no change) respectively. In the resilient community, $0 \%, 90.7 \%$ and $9.3 \%$ of households perceived the onset of the rains to be early onset, late onset and same onset respectively. A Pearson correlation $(\mathrm{R}=0.175)$ statistically significant (at $\mathrm{p}<0.05$ ) shows a weak correlation between household perceptions of onset of the rainfall pattern among the two studied communities hence the variations in the perceptions is due to chance. There is also significant variation in the perception of households among the two communities about the consequence of the onset of the rainfall for farming activities. $100 \%$ of households in the vulnerable community perceived the onset of the rains (which they describe as highly erratic) to be a problem for farming activities. On the part of the resilient community, $86.7 \%$ of households perceive the onset of the rainfall (late onset and stops early) to have consequence for farming activities whiles $13.3 \%$ perceive the onsets of the rains (late onset) to have no consequence on farming activities.

Households noticed that the erratic rainfall pattern which starts late May/ early June and stops early, around late September or early October posses serious constraints for their farming activities (including post harvest losses, poor germination, crop failure, stunted growth and withering and wilting of crops).

In FGDs held across the two communities, Discussant solidly all together indicated that for the past two to three decades, planting time/month has shifted to late May or early June and more recently (2014/2015) to middle or late June. This finding, which is consistent with many other researches (see In Ghana, [3]; in Ethopia, [6]; [18] is an indication that the onset of rainfall has shifted from May to June which is not suitable for some crops such as millet and sorghum. [18] indicated that, in the past people could see fully germinated crops by July and matured crops by August. However, the rains that normally used to start in mid-June have shifted to July and stops much earlier (mid-September) which presents challenges for farmers. [22] also evidenced that, changes in rainfall pattern and intensity results in the change of planting season, increased risk of crop failure, stunted growth and drying of crops. [37] noted that, in Africa, droughts are a widespread phenomenon, which occurs in between three and five years.

\subsection{Household Perception of Good Rainfall Regimes or Years}

Households were asked to state year or number of years or decade perceived to be a good rainfall year or decade. In all the two studied communities, $7.7 \%$ indicated the periods before the 1940s where years with good rainfall. $9 \%$ of respondents perceived the periods $1941-1950$ as the good rainfall decade, $7.3 \%$ indicated 1951-1960, 14.7\% indicated 1961-1970, 1971-1980 was $18 \%$ whiles $1981-1990$, 19912000, 2001-2010 and 2011+ were 5.7\%, 24\%. 13.3\% and $2 \%$ respectively. In an interview with a key informant, he referred to Good rainfall years as periods when crops have inadequate water to grow fully and produce satisfactory yields. Since diverse crops and grasses have distinct moisture needs in different stages of plant growth, it is sometimes difficult to describe the amount of rainfall needed because large varieties of crops are being cultivated. Good rainfall can appropriately be defined relative to human beings needs by associating good rains to the crops or fodder cultivated in an area. This observation is consistent with the observation of [35] and [25:5]. A Pearson correlation $(\mathrm{R}=-0.493)$ statistically significant $($ at $p<0.005)$ shows a negative correlation (inverse relationship) between age of respondents and their perception about good rainfall years. This implies that, the perception of good rainfall years was inversely related to respondents' age.

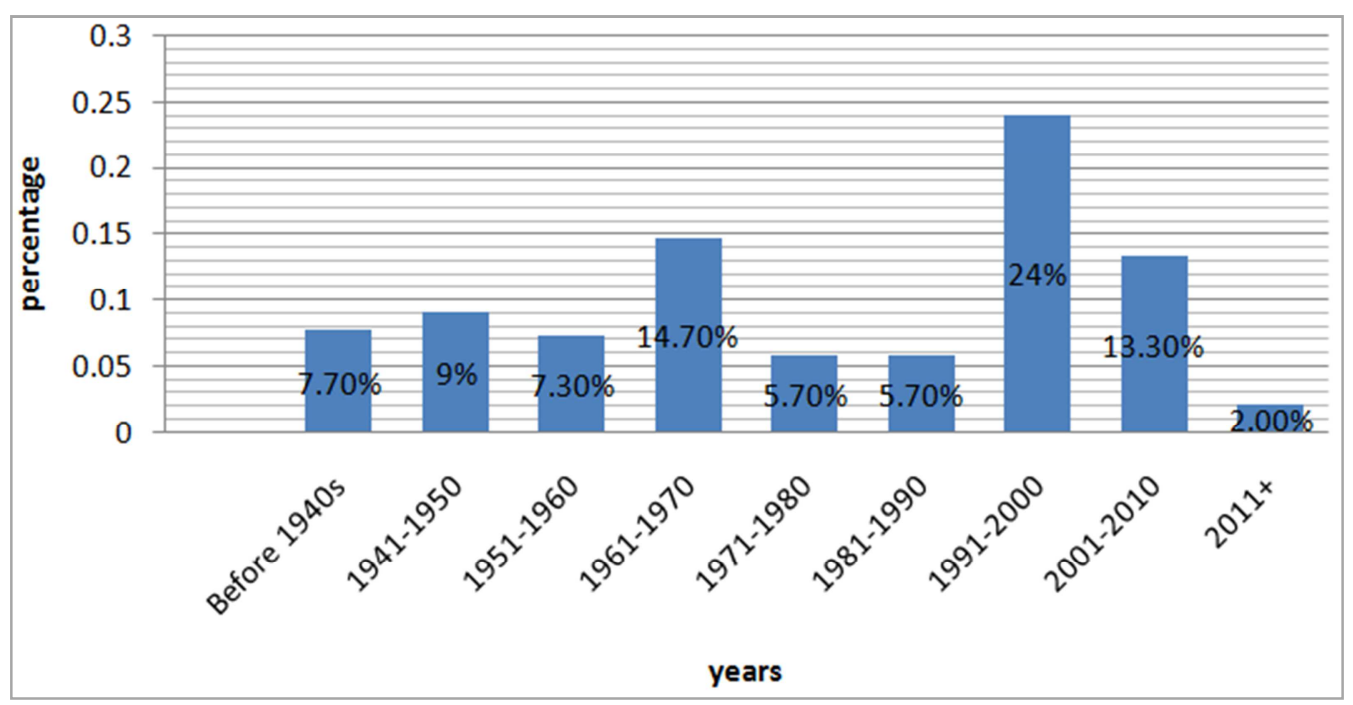

Source: Field Survey, 2015. 


\subsection{Corroborating the Extent of Climate Change in the Study District}

To assess the extent of climate change in the study district, a time series analysis of climate (rainfall and temperature) data obtained from the Ghana Meteorological Agency (GMA) was conducted.

\subsection{Corroboration of Rainfall Variability in the Study District with GMA Records}

Evidence of rainfall variability in the Bongo district is provided by climatic records from 1982-2012 obtained from the GMA, the records as shown in (figure 5) indicate that, there have been some hydro-climatological changes within the study district and region at large. The climate time span was restricted to 30 years (from 1982-2012), due to limitations on the availability of climate records at the GMA (Vea Weather station). Notwithstanding, this time frame interval is arguably sufficient to permit the establishment of the degree and magnitude of the dynamics between the livelihood context and climate change in the Bongo district.

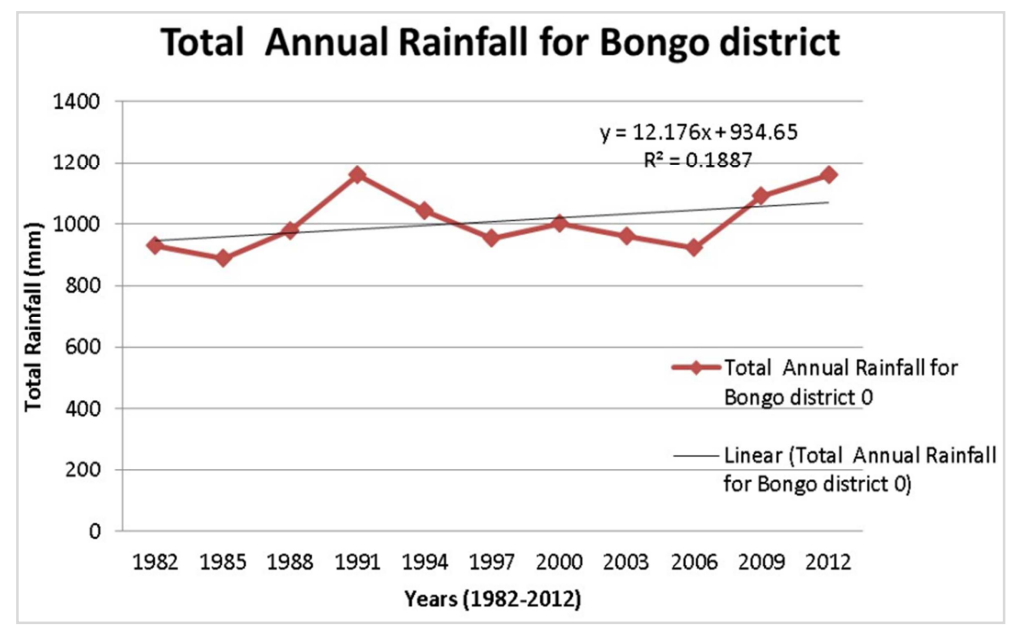

Source: GMA, 2015.

Figure 5. Total Annual Rainfall for the Bongo District.

Figure 5 shows that rainfall variability has been detected in the Bongo district. For instance, the district recorded the lowest rainfall amount of $890.4 \mathrm{~mm}$ in 1985, followed by a succession of erratic rainfall patterns until 1991 and 2012 when the district recorded its highest rainfall amount of 1158.1 mm (Figure 5). According to officials of MoFA both at the district and regional offices in the Bongo district and Bolgatanga municipal respectively, the area requires at least $950 \mathrm{~mm}$ of rainfall for crop production (see [4]; [3]). Therefore, considering $950 \mathrm{~mm}$ as the baseline, there has been 13 \{drought years over a period of 30 years that could be considered risky for crop production. Data from the Ghana Meteorological Agency suggest that within the UE/R there have been major drought seasons in 1982, 1983, 1984, 1985, 1986, 1987, 1990, 1995, 2002, 2004, 2005, 2006 and 2007. Confirming this study results, 1983, 1984, were also identified by [3] as years with drought seasons. This reduction in rainfall amounts (GMA records) confirms the field observations of households perception that the rainfall regime has become highly variable, reduced amount and erratic.

The research findings of a reduced and highly erratic and short rainy season associates reasonable credibility to other researches which suggest significant decreases in rainfall amount in Sub-Saharan Africa, including Ghana (see [7]; [3]). In a FGD, discussant strongly noted that, as far as farming activities are concerned, the early onset of the rains is as important as the amount or quantity of the rainfall.

The mean annual rainfall in the Bongo district for the 30 years was $915 \mathrm{~mm}$. The mean annual rainfall (915) is not sufficient for crop production; also, the amount of rainfall is not fairly distributed in the growing months. The long-term mean rainfall showed that between $60 \%-75 \%$ of the total amount of rainfall in a year is concentrated into two wettest months (July and August) worsening and intensifying soil erosion, floods and destruction of properties, collapse of buildings among others. These findings are in tandem with the [37] which indicated that rainfall in Ghana has decreased to low levels in the late 1970's and early 1980's, resulting in an overall decreasing trend between the period 1960 to 2006 , with an average precipitation of $2.3 \mathrm{~mm}$ per month $(2.4 \%)$ per decade [37]. This research disagrees with [35] who suggests that, the mean seasonal concentration of rainfall does not present difficulties to farmers. He contended that, the difficulty rests on the point that the distribution of rainfall fluctuates from year to year. The rainfall pattern of the study district is therefore classified as an intra-annual variability or seasonal concentration since the distribution of rainfall is within a particular year and generates seasonality in the agricultural cycle, labour demands, food availability, food prices, the prices of consumer goods and labour, health, births, deaths and migration patterns [35]. 


\subsection{Households Perception About Changes in Temperature}

Approximately $96 \%$ of households in the vulnerable community perceived changes in temperature during the growing season in their life time whiles $4 \%$ perceived no changes in the temperature pattern. In the resilient community, $90.7 \%$ of households' perceived changes in temperature pattern whiles $9.3 \%$ observed/perceived no changes in temperature. Among the believers of temperature changes, $78.7 \%$ of the households in the vulnerable community perceived the temperature to be increasing (hotter), $14.7 \%$ observed decreasing (cooler) temperature whiles $6.7 \%$ observed the temperature pattern to be the same (no change). There is a little variation in the resilient community, in which $74.7 \%, 17.3 \%$ and $8 \%$ perceived the temperature in the growing season to be hotter(increasing), cooler (decreasing) and same (no change) respectively. $98.7 \%$ and $80 \%$ of households in the vulnerable and resilient communities respectively perceived the changes in the temperature pattern to have problems for their farming activities. A Pearson correlation $(\mathrm{R}=0.302)$ statistically significant (at $p<0.005)$ shows a weak positive correlation between the resilient and vulnerable community's household perception about the problems temperature change presents for their farming activities.

Perceived changes in temperature were reiterated by $\mathrm{FG}$ Discussants in both resilient and vulnerable communities which ascertained the increment of temperature in their localities. Key informant interview gathered that, because of increasing temperature during the Dawooliga months (March, April and May), crops usually do not germinate well and there is always high prevalence of diseases in both humans and animals (for example anthrax, miseales). Furthermore, streams, ponds and dug-outs and rivers tremendously declined or dry up during the dry season because of high evapo-transpiration and low underground water table. Apparently, the key indicators of rainfall and temperature variability are the high rate of diseases and pest, poor germination, withering of crops, change in the planting time/months for the major crops and the disappearance of some fauna and flora.

\subsection{Corroboration of Temperature Changes in the Study District with GMA Records}

Another vital component for agricultural production in the study district is temperature. A time series analysis of maximum and minimum annual temperatures in the Bongo district obtained from the GMA reveals significant variations in annual temperatures for the three decades (1982-2012). The Bongo district recorded an increase of $0.6^{\circ} \mathrm{C}$ for the minimum temperature over the period 1982 - 2012. Figure 6 reveals an average minimum temperature of $22.4^{\circ} \mathrm{C}$ in 1982 and $23.0^{\circ} \mathrm{C}$ in 2012 , which denotes an upsurge of $0.6^{\circ} \mathrm{C}$.

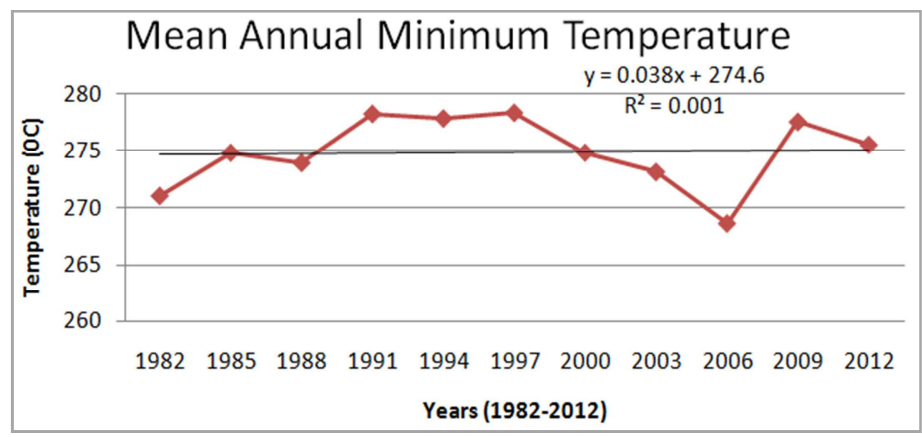

Source: GMA, July 2015.

Figure 6. Mean Annual Minimum Temperature For The Bongo District.

Comparable trend is detected for the maximum annual temperature in the district (figure 7) which indicates that maximum annual temperature have been fluctuating with $34.1^{\circ} \mathrm{C}$ in 1982 to $34.8^{\circ} \mathrm{C}$ in 2012 . This denotes a rise of $0.7^{\circ} \mathrm{C}$. Undoubtedly, numerous researches have corroborated the upsurge in the temperature movement in most parts of Africa (e.g. [7]; [10]; [32]; [3]; [37]).

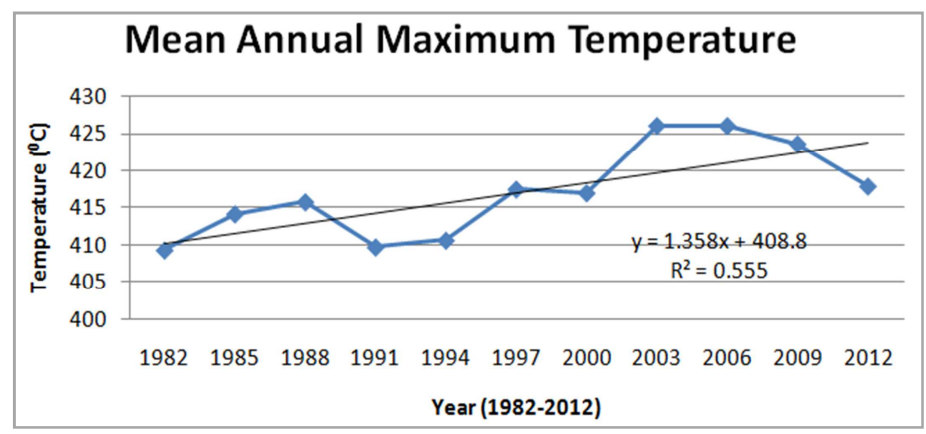

Source: GMA, July 2015.

Figure 7. Mean Annual Maximum Temperature for the Bongo District. 
The findings indicate that there is an intense vulnerability of crop production to droughts in the district. Also, the findings imply that the vulnerability of the district is topmost in the Gowrie Kunkua more than the Soe Kabre community and this is characterized by minimal access to economic and physical assets, poor soil fertility, inadequate agricultural land, erosion and high rate of pest and disease [14]. [3] noted that, continuous cropping of farm lands in the Upper East region without the addition of appropriate soil amendments has left the soil with low fertility and in a highly unproductive state.

The major crops grown in the study area such as millet, sorghum, guinea corn and maize [26] require an appreciable amount of water during growth and persistent droughts and high temperature have often resulted in low production from such crops [3]. High poverty levels in the district make it difficult for smallholder households to afford fertilizers to improve soil fertility. Again, low socio-economic development and erratic rainfall patterns (in terms of onset, amount and duration) compel smallholder households in the Bongo district enormously susceptible to the negative impacts of climate change since the main livelihood activities is rain-fed Agriculture [26].

The two communities (all in Bongo district) in general experience a uni-modal rainfall pattern and are largely characterized by drier conditions and fragile agroecosystems. As such, these types of communities are liable to be vulnerable to climate change. Declining rainfall in the study district, connected with imminent predictions of rise in annual temperature poses dangerous challenges to households in the communities since they rely solely on rainfall for crop production and other rural livelihoods [12]. Rising temperature increases evaporation and evapotranspiration that leads to a decline in soil moisture content. Although temperature is vital for crop production, rainfall is more crucial for crop production in the tropics. This is possibly attributed to the fact that a lack of or excess of rainfall could possibly culminate to either drought or flooding that can reduce crop production and hence lead to food shortages [15]. Given this fact, rainfall is particularly important than temperature since farming activities in the district are dependent on rainfall. Droughts are the main threat to farming systems [33], therefore the pattern and duration of the rainfall are significant determinants of crop productivity in the Bongo district and Ghana at large [21]. A study by [23] suggests that, inadequate rainfall distribution is perceived by households to be the major trigger of decline in crop productivity in rain-fed agriculture communities across Africa. Lessen rainfall amount can potentially influence water flow into water bodies. The perceptions of households in the study communities about changes in rainfall and temperature patterns (decrease in rainfall and rise in temperature, late onset and erratic rainfall regimes) were all corroborated and strongly authenticated by rainfall and temperature data obtained from the GMA. This discovery is a clear indication that climate change is occurring and poses negative impacts on the livelihood of smallholder households in the Bongo district and the Upper East in general.

\subsection{Perceived Causes of Changing Rainfall and Temperature Pattern}

Although there is great belief and certainty that the climate is changing, there is disparity in opinion of what is responsible/behind the changing climate. In this study, approximately $28.4 \%$ of households in the vulnerable community perceive bush burning to be the cause of climate change $\{$ hegemonic representation\}, 33.3\% indicated deforestation is responsible for the current climate problems \{hegemonic representation\} whiles $22.4 \%$ perceived climate change is caused by breaking of taboos by community members and the disrespect for life forces (ancestors, earth gods, spirits and spirit medium) (polemic representation $\} .12 .9 \%$ and $3 \%$ suggested emission of fossil fuels \{hegemonic representation\} and other causes respectively (particularly e.g. the will of the gods, shedding innocent blood-killing people, sexual intercourse and abortion and unexplained factors) \{polemic representation\}. On the part of the Soe Kabre community, there are slid variations in perception with $15.4 \%$ alluding to Bush burning as the cause of climate change and weather extremes $\{$ hegemonic representation\}, 35.4\% blamed the changing rainfall and temperature pattern on deforestation (indiscriminate felling of trees for various uses) \{hegemonic representation $\}, 24.6 \%$ also perceived breaking of taboos and the disrespect for life forces as being responsible for the climate woes \{polemic representation\} whiles $5.4 \%$ identified emission of fossil fuel \{hegemonic representation \} and $19.2 \%$ identified other causes such as the will of the gods (unexplained), shedding innocent blood-killing people, sexual intercourse and abortion among others \{polemic representation\} were identified as the root causes of climate change particularly droughts, floods and high temperatures.

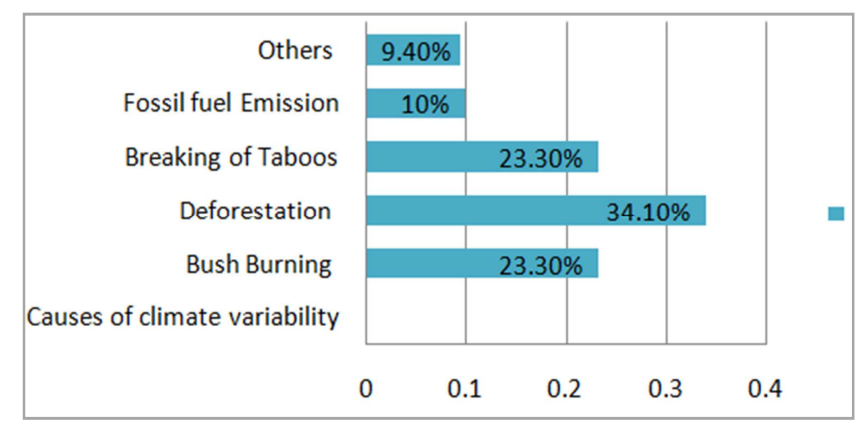

Source: Field survey, 2015.

Figure 8. Causes of Changes in Rainfall and Temperature.

In total, $23.3 \%$ of households in both communities associate climate change to bush burning\{hegemonic representation\}, $34.1 \%$ perceived deforestation to be the 
cause of climate change \{hegemonic representation\}, whiles $23.3 \%$ perceived breaking of taboos and the disrespect for the beliefs, spirits, gods (life forces) as being responsible for climate change \{polemic representation\}. $10 \%$ and $9.4 \%$ perceived the emission of fossil fuel \{hegemonic representation\}, and other causes (natural or nature/will of gods-unexplained) respectively to be the underlining causes of climate change \{polemic representation\} (Figure 8).

The education and training of households influenced significantly their perceptions about the causes of climate change. The educated households, mostly aligned climate change to ozone layer depletion caused by emission of fossil fuel (vehicles and industries) \{hegemonic representation\}. In a study by [30], educated respondents in a FGD noted that, climate change is caused by "the production and use of ammunitions by the white men coupled with the use of motorbikes which destroys the ozone layer and increases the intensity of the sunrays reaching the earth resulting in climate change". Others argue that, "I do not agree with the fact that climate change is caused by cutting down of trees since they are replaced with plantation farming" [30]. This suggests that literate households does not align cutting of trees as the cause of climate change, but rather suggest emission of fossil fuel. The findings of [30] support this research finding in which educated households align climate change to depletion of the ozone layer due to excessive fossil fuel emission from industrialization.

Conversely, in a FGD held in both communities, An overwhelming majority of discussant when asked the causes of climate change said "climate change is caused by cultural forces, which include lack of respect for sacred places such as groves, shrines and ponds -local rivers, rise in Christianity and Islam (who describe the African belief system as evil and satanic), random cutting down of sacred trees, non-performance of rain-making ceremonies, killing humans for rituals and human sacrifices, among other cultural beliefs are the main causes of changing rainfall and temperature \{polemic representation\}. Others said. Our bad farming practices such as bush burning, the use of chemicals in farming, cutting down of trees for firewood and charcoal production causes the poor rainfall and high temperature\{hegemonic representation\} which consequently affect our farm yield... \{emancipated representation\}. The findings all point to the fact that, climate change is caused by natural (or nature) and anthropogenic factors. The findings are further consistent with the study by [28] who reported that $40 \%$ of farmers attributed changes in weather patterns to natural causes viz a viz the will of God, or the result of changing times (unexplained) while some aligned climate change with tradition [28]. The findings of [28], [30], [22], all confirms this present study. A Mann-Whitney U test was conducted, statistically significant (at $\mathrm{p}<0.05$ ) shows that the distribution of causes of changing rainfall and temperature pattern is the same across the study communities.

The study further revealed that, $80 \%$ of households who believed climate change has occurred and/or is occurring adopted or implemented some coping and adaptation measures, $29.6 \%$ of households who associate climate change to cultural factors such as the will of the gods (unexplained), shedding innocent blood (killing people), sexual intercourse and abortion, disrespect for life forces (sacred groves, shrines, the earth priest, ancestors etc.) did not adopt or implement adaptation strategies. The majority of those who adopted/implemented adaptation measures $(62.7 \%)$ associated climate change to anthropogenic factors such as bush burning, deforestation and emission of fossil fuel. This is consistent with [22] study, where $58.02 \%$ of climate change believers that asserted that climate change is as a result of anthropogenic reasons adopted. Discussants in a FGD (both communities) unanimously affirmed that, climate change poses greater risk for their farming and livelihoods through the declining crop and animal production \{emancipated representation\}. To [1], the basic cause of climate change is the increase in the concentration of carbon dioxide and other greenhouse gases in the atmosphere as a result of human activities mostly fossil fuel burning and clearing of forests and this assertion is in conformity with the present study. [1] opined that, at the global scale, the major cause of greenhouse gas (GHG) emissions are from carbon dioxide (70\%), largely from burning of fossil fuel (petroleum), while the other sources of GHG are methane $\left(\mathrm{CH}_{4}\right)$ and nitrous oxide $\left(\mathrm{N}_{2} \mathrm{O}\right)$ triggered by agricultural activities and deforestation specifically the use of chemicals and pesticides and this contention is coherent with this study. This study is also in accordance with the [34] postulation that, intensifying fossil fuel burning and changes in land use have emitted, and are continuing to emit, higher quantities of GHG into the earth's atmosphere. GHG and aerosols affect climate by altering incoming solar radiation and outgoing infrared (thermal) radiation that are part of earth's energy balance [34].

\section{Conclusions}

Smallholder Households' observed changes in the rainfall and temperature patterns. Households indicated that the rainfall pattern has become highly erratic, short and reduced amount of rainfall whiles temperature for the growing season have become hotter. Households indicated that all these changes present severe consequences for their farming activities and livelihoods. These views and perceptions by households were corroborated by rainfall and temperature records from the GMA in the study district. There are strong indications that climate change posses serious constraints the risk for the livelihoods of smallholder household in the Upper East Region and the country at large. Therefore, livelihood diversification strategies, including non-farm income sources should be robustly pursued by policy makers in these communities. Policy makers need to formulate more specific and targeted climate adaptation policies to reduce the vulnerabilities of smallholder households whose livelihoods depend largely on rain-fed agriculture. 


\section{References}

[1] Abate L., (2011). "Assessment of Climate variability Effects on Rain Fed Crop Production and Coping Mechanisms: The Case of Smallholder Farmers of West Shoa Zone, Oromia, Ethiopia”. A Master's Thesis Submitted to The Graduate Program of Addis Ababa University Environmental Science Program Adaptations by Ethiopian Pastoralists, Addis Ababa, Ethiopia.

[2] Aniah P., Wedam E., Pukunyiem M. and Yinimi G., (2013). "Erosion and livelihood change in North East Ghana: A look into the bowl". International Journal of Sciences: Basic and Applied Research (IJSBAR) ISSN 2307-4531.

[3] Antwi-Agyei P., (2012). "Vulnerability and adaptation of Ghana's food production systems and rural livelihoods to climate variability". School of Earth and Environment, University of Leeds, UK.

[4] Assan J. K., Caminade C. and Obeng F., (2009). "Environmental variability and vulnerable livelihoods: minimizing risks and optimizing opportunities for poverty alleviation". Journal of International Development, 21(3): 403-418.

[5] Barrett C. B., Reardon T. and Webb P. (2001). "Nonfarm income diversification and household livelihood strategies in rural Africa: concepts, dynamics, and policy implications". Food Policy, 26(4): 315-331.

[6] Berlie A. B., (2013). "Determinants of Rural Household Food Security in Drought-Prone Areas of Ethiopia: Case study in Lay Gaint District, Amhara Region". 45549273. University of South Africa.

[7] Boko, M., I. Niang, A. Nyong, C. Vogel, A. Githeko, M. Medany, B. Osman-Elasha, R. Taboand P. Yanda, 2007: Africa. Climate Change 2007: Impacts, Adaptation and Vulnerability. Contribution of Working Group II to the Fourth Assessment Report of the Intergovernmental Panel on Climate Change, M. L. Parry, O. F. Canziani, J. P. Palutikof, P. J. van der Linden and C. E. Hanson, Eds., Cambridge University Press, Cambridge UK, 433-467.

[8] Boykoff, M. T. \& Boykoff, J. M. (2004). Bias as balance: Global warming and the U. S.

[9] Breakwell, G. M. (2001). Social representational constraints upon identity processes. In K. Deauxand G. Philogène (eds.), Representations of the social: Bridging theoretical traditions (pp. 271-284). Oxford: Blackwell.

[10] Christensen J. H., Hewitson B., Busuioc A., Chen A., Gao X., Held R., Jones R., Kolli R. K., Kwon W. and Laprise R., (2007). Regional climate projections: climate change (2007): The Physical Science Basis. Contribution of Working Group I to the Fourth Assessment Report of the Intergovernmental Panel on Climate Change. Cambridge: University Press.

[11] Dietz T., Millar D., Dittoh S., Obeng F., and Ofori-Sarpong E., (2004). Climate and Livelihood Change in North East Ghana. In: A. J. Dietz, R. Ruben\& A. Verhagen, eds, The Impact of Climate variability on Dry lands, with a Focus on West Africa. Dordrecht/Boston/ London: Kluwer Academic Publishers. Environment and Policy Series, Vol. 39, pp. 149-172.

[12] E. P. A., (2007). Climate change and the Ghanaian economy.
Policy Advice Series Volume 1. Accra: Environmental Protection Agency, Ghana.

[13] Gang X., (1999). Estimating Sample Size for a Descriptive Study in Quantitative Research. Quirks Marketing Research Review, June 1999.

[14] Ghana Statistical Service, (2014). Revised annual 2014 Gross Domestic Product. Accra, Ghana: Ghana Statistical Service.

[15] Haile, M. (2005). Weather patterns, food security and humanitarian response in sub-Saharan Africa. Philosophical Transactions of the Royal Society, 360(1463): 2169.

[16] Hulme, M. (2009). Why we disagree about climate change. Cambridge: Cambridge.

[17] Jaspal, R., Nerlich, B. \& Koteyko, N. (2013). Contesting science by appealing to its norms: Readers discuss climate science in The Daily Mail. Science Communication. 35(3), $383-410$.

[18] Kassa, T., Van Rompaey, A., Poesen, J., Yemane, W. and Deckers, J. (2012). Impact of Climate Change on SmallHolder Farming: A Case of Eastern.

[19] Tigray, Northern of Ethiopia. Journal of African CropScience20: 337-347. African Crop Science Society.

[20] Leedy, P. D (1997). Practical Research Planning and Design. (6th Edition). Prentice-Hall, New Jersey.

[21] Lobell, D. B. \& Burke, M. B. (2008). Why are agricultural impacts of climate change so uncertain? The importance of temperature relative to precipitation. Environmental Research Letters, 3: p. 034007.

[22] Menapace L., Colson G., and Raffaelli R., (2014). Farmers' Climate Change Risk Perceptions: An Application of the Exchangeability Method. Paper prepared for presentation at the EAAE 2014 Congress 'Agri-Food and Rural Innovations for Healthier Societies' August 26 to 29, 2014, Ljubljana, Slovenia.

[23] Mertz, O., C. Mbow, J. O. Nielsen, A. Maiga, D. Diallo, A. Reenberg, A. Diouf, B. Barbier, I. B. Moussa, M. Zorom, I. Ouattara, and D. Dabi, (2010). Climate factors play a limited role for past adaptation strategies in West Africa. Ecology and Society, 15(4), 25, www.ecologyandsociety.org/vol15/iss4/art25/

[24] Mertz, O., Halsnæs, K., Olesen, J., and Rasmussen, K., (2009). Adaptation to Climate Change in Developing Countries. Environmental Management, 43(5), 743-752. doi: 10.1007/s00267-008-9259-3.

[25] Mishra, A. K. \& Singh, V. P. (2010). A review of drought concepts. Journal of Hydrology, 391(1-2): 202-216.

[26] MOFA. (2007). Food and agriculture sector development policy. Accra: Ministry of Food and Agriculture.

[27] Moscovici, S. (1988). Notes towards a description of social representations. European Journal of Social Psychology, 18, 211-250.

[28] Mtambanengwe F., Mapfumo P., Chikowo R. and Chamboko T., (2012). Climate Change and Variability: Smallholder Farming Communities inZimbabwe Portray a Varied Understanding. African Crop Science Journal, Vol. 20, Issue Supplement s2, pp. 227 - 241. ISSN 1021-9730/2012. 
[29] Nigussie, A. and Girmay, T. (2010). Farm-Level Climate Change Adaptation in Drought-Prone Areas of Ethiopia: Three Drought-Prone areas of Tigray, Ethiopia. Paper Presented in the 117th European Association of Agricultural Economists. Hohenheim Castel, Stuttgart, Germany, 25-27 November, 2010. press. Global Environmental Change, 14, 125-136.

[30] Sakyi E. K. and Lassey R. A., (2015). Understanding the Causes and Threats of Climate Change in Rural Ghana: Perspectives of Smallholder Farmers. Ontario International Development Agency, Canada. International Journal of Sustainable Development 08:02 (2015) ISSN 1923-6654 (print) ISSN 1923-6662 (online). Available at http://www.ssrn.com/link/OIDA-Intl-Journal-SustainableDev.html

[31] Sarantakos, S. (2005). Social Research, Pelgrave Macmillan, New York. p. 190-120.

[32] Stanturf, J. A., Warren, M. L., Charnley, S., Polasky, S. C., Goodrick, S. L., Frederick Armah, F., and Nyako, Y. A. (2011). Ghana climate change vulnerability and adaptation assessment. Washington, DC: USAID.
[33] UNDP. (2007). Human Development Report 2007/2008: fighting climate change: human solidarity in a divided world. New York: United Nations Development Programme.

[34] UNFCCC. (2007). Climate variability: Impacts, Vulnerabilities and Adaptation. University Press, Cambridge. University Press.

[35] Van der Geest, K. (2004). "We are managing!" Climate change and livelihood vulnerability in Northwest Ghana. Leiden: African Studies Centre, ASC Research Reports 74.

[36] Vogel, C., (2005) "Seven fat years and seven lean years?" Climate change and agriculture In Africa. IDS Bull., 36, 3035 .

[37] World Bank, (2011). Climate Risk and Adaptation Country Profile: Vulnerability, Risk Reduction, and Adaptation to Climate Change-Papua New Guinea (GFDRR, Trans.) (pp. 112). Washington, DC 20433: World Bank. 